\title{
Efektivitas Social Media Marketing E-Commerce dalam Meningkatkan Brand Image Perusahaan (Survei Pada Pelanggan Tokopedia)
}

\author{
Defrianto, Riris Loisa \\ defrianto.ng@gmail.com,ririsl@fikom.untar.ac.id
}

Fakultas Ilmu Komunikasi Universitas Tarumanagara

\begin{abstract}
The research was done to determine the impact the of social media marketing will have on brand image Tokopedia. The research uses marketing communication theory, social media marketing, and brand image. Tokopedia is an e-commerce that offers a variety of products for its users starting with bill payment, electronics, beauty, automotive, and daily necessities. The approach used for this study is a quantitative approach with a survey method. The population in this study is the user of Tokopedia and the number of samples taken as much as 218 individuals and are using nonprobability sampling techniques with the purposive sampling approach. The data collected in this study is from a questionnaire. Based on the results of the research, it has been obtained that partial, there is an impact that social media marketing has had on the brand image Tokopedia. On the dimension of social media marketing, communication indicators are the highest indicator, and on the brand image dimension, brand benefit and competence indicators are the highest indicator. The relation that happened is only $28,3 \%$. The rest of the $71,7 \%$ are affected by other factors outside the social media marketing activity.
\end{abstract}

Keywords: brand image, e-commerce, social media marketing

\begin{abstract}
Abstrak
Penelitian ini dilakukan untuk mengetahui pengaruh social media marketing terhadap brand image Tokopedia. Penelitian ini menggunakan teori komunikasi pemasaran, social media marketing, dan brand image. Tokopedia merupakan e-commerce yang menawarkan berbagai macam produk-produk untuk penggunanya dimulai dari pembayaran tagihan, elektronik, kecantikan, otomotif, dan kebutuhan sehari-hari. Pendekatan yang digunakan untuk penelitian ini adalah pendekatan kuantitatif dengan metode survey. Populasi dalam penelitian ini adalah pengguna Tokopedia dan jumlah sampel yang diambil sebanyak 218 orang dan menggunakan teknik nonprobability sampling dengan pendekatan purposive sampling. Data yang dikumpulkan dalam penelitian ini dengan menggunakan kuisioner. Berdasarkan hasil penelitian, maka diperoleh hasil bahwa secara parsial, ada pengaruh social media marketing terhadap brand image Tokopedia. Pada dimensi social media marketing, indikator komunikasi merupakan indikator yang tertinggi, dan pada dimensi brand image, indikator brand benefit and competence merupakan indikator tertinggi. Hubungan yang terjadi hanya sebesar $28,3 \%$. Sisanya $71,7 \%$ dipengaruhi oleh faktor lain diluar kegiatan social media marketing.
\end{abstract}

Kata Kunci: brand image, e-commerce, social media marketing 


\section{Pendahuluan}

Perkembangan teknologi yang kian cepat di era ini, membuat strategi pemasaran terus berevolusi dari metode pemasaran tradisional hingga menjadi metode pemasaran yang modern (Jurnal.id, n.d). Akibat dari cepatnya perkembangan teknologi memaksa pengusaha lama untuk mengembangkan cara strategi pemasaran yang baru seperti direct-mail menjadi e-mail, cetak (print) menjadi situs web, siaran televisi menjadi online video advertising (Jurnal.id, n.d).

Dalam memasarkan inovasi dan kreativitasnya perusahaan melakukan berbagai strategi pemasaran baru yang dilakukan untuk menarik daya tarik konsumen baru untuk menggunakan jasa maupun produk dari perusahaan tersebut. Saat ini perusahaan e-commerce lama maupun pemain baru sedang berlomba-lomba dalam melakukan strategi pemasaran modern melalui media digital dalam memasarkan aktivitas dan inovatif dalam meningkatkan brand awareness, brand image perusahaan melalui digital marketing, advertising dan social media marketing, dan salah satunya yang telah melakukannya adalah Tokopedia.

Pada website Aseanup.com tertulis bahwa Tokopedia merupakan e-commerce yang terurut di peringkat satu dari sepuluh perusahaan terbesar di Indonesia dengan perkiraan lalu lintas penggunanya sejumlah 148,500,000 selama per bulannya. Tokopedia adalah kategori e-commerce C2C (Customer to Customer), yang merupakan sarana bertemunya penjual dan pembeli dalam melakukan transaksi penjualan (Kotler \& Armstrong, 2010). Tokopedia merupakan e-commerce yang menyediakan beragam produk-produk untuk penggunanya dimulai dari pembayaran tagihan, elektronik, kecantikan, otomotif, dan kebutuhan sehari-hari.

Namun Tokopedia juga melakukan pemasaran dalam mensukseskan program maupun kampanyenya. Menurut Kotler dan Armstrong (2012) manajemen pemasaran adalah sebuah program yang dilakukan oleh perusahaan dalam membentuk sebuah pandangan untuk para konsumen serta membentuk hubungan yang erat agar terciptanya nilai tersebut bagi para pelanggannya. Di sisi lain menurut Kotler dan Keller (2012), bauran komunikasi pemasaran terdiri dari delapan jenis komunikasi, yakni iklan, promosi penjualan, acara dan pengalaman, hubungan masyarakat dan publisitas, pemasaran langsung, pemasaran interaktif, pemasaran dari mulut ke mulut, dan penjualan personal. Kegiatan pemasaran yang dilakukan Tokopedia antara lain periklanan, dan hubungan masyarakat dan publisitas.

Seiring perkembangan waktu strategi pemasaran yang dilakukan sebuah perusahaan akan berkembang termasuk Tokopedia, menurut Morrisan (2012) komunikasi pemasaran terpadu merupakan sebuah kegiatan pemasaran dan promosi dalam meningkatkan brand image perusahaan dimata konsumen pada kasus tersebut Tokopedia juga telah melakukannya melalui media sosialnya dalam memasarkan kampanye barunya yakni \#mulaiajadulu. Dalam jurnal Sinaga dalam Lazer dan Kelly (2017) mendefinisikan social media marketing merupakan aplikasi ilmu pemasaran, konsep dan teknik yang bertujuan untuk meningkatkan kesejahteraan dan tujuan ekonomi. Social media marketing tidak semata mengenai promosi di halaman suatu website melainkan dapat berfungsi sebagai sebuah rencana dan metode dalam membentuk sebuah pengaruh dan reputasi perusahaan di komunitas pelanggan potensial, serta pembaca maupun pendukung. Hal ini sejalan dengan apa yang telah dilakukan Tokopedia dalam memasarkan kampenyanya \#mulaiajadulu dalam kampanyenya Tokopedia berusaha membangun pengaruh dengan menggunakan social media marketing. Manfaat dalam penggunaan social media marketing menurut 
Candraningrum, dan Aulia, (2019) yakni sebagai berikut, dapat menciptakan loyal customer, meningkatkan traffic dan exposure yang bagus untuk web, berpengaruh terhadap SEO dan hasil search di Google, serta dapat meningkatkan sales.

Pada umumnya konsumen akan membuat keputusan dalam melakukan pembelian terhadap sebuah produk, konsumen akan memperhatikan citra dari suatu merek (brand image) tersebut. Menurut Lee, James, Jeffrey, dan Kim, dalam Reynolds \& Gutman, (2014) mendefinisikan brand image adalah sekumpulan makna dan asosiasi yang dapat membedakan sebuah produk atau layanan perusahaan dengan pesaingnya. Disisi lain, menurut Yulianti, Suryana, dan Zein dalam Shrimp, 2012) menyatakan bahwa brand image dapat beranggapan semacam sebuah asosiasi yang teringat oleh sebuah merek tertentu. Hal ini sejalan dengan apa yang diinginkan Tokopedia melalui kampanyenya \#mulaiajadulu brand image dari Tokopedia akan semakin kuat, semakin dikenal, dan penggunanya akan tetap menggunakan layanannya dalam melakukan proses jual beli barang.

\section{Metode Penelitian}

Pendekatan pada penelitian ini menggunakan pendekatan penelitian kuantitatif. Metode penelitian kuantitatif menurut Saebani (2017) mendefinisikan sebagai pengumpulan data dan dalam penafsiran data banyak menggunakan angka disertai dengan gambar, tabel, grafik, dan cara lainnya yang dapat digunakan sebagai hasil pengukuran dari sebuah penelitian. Dalam penjelasan lainnya, menyatakan bahwa pada saat melaksanakan pengumpulan data ada beberapa cara yang dapat dilakukan seperti melalui: angket, wawancara, pengalaman, ujian (tes), dokumentasi, dan sebagainya. Menurut Kriyantono (2016) survei adalah sebuah cara dalam mengumpulkan dan menganalisis data yang bersifat sangat tertata dan mendetail melalui kuesioner sebagai cara untuk mendapatkan informasi yang mewakili populasi.

Berdasarkan data yang diakses melalui Aseanup.com perkiraan lalu lintas pengguna sebanyak 148,500,000 selama per bulan. Penelitian ini menetapkan 218 responden, dengan kriteria sampel yang sudah dipilih dan selaras dengan penelitian peneliti.

Teknik penentuan sampel yang digunakan pada penelitian ini didasarkan pada metode non probability sampling, dengan menggunakan pendekatan purposive sampling. Data dikumpulkan dengan penyebaran kuesioner dengan menggunakan skala likert. Data primer dalam penelitian ini diperoleh melalui penyebaran kuesioner. Sedangkan data sekunder dalam penelitian ini diperoleh melalui studi kepustakaan dan internet. Untuk mengetahui keabsahan data dalam penelitian ini, peneliti menggunakan uji validitas, dan uji reabilitas. Sedangkan untuk pengelolah data dalam penelitian ini, peneliti menggunakan uji koefisien korelasi sederhana, uji koefisien determinasi, analisis regresi linear sederhana, dan uji t. Hipotesis dalam penelitian ini adalah sebagai berikut:

Ha: terdapat pengaruh social media marketing terhadap brand image Tokopedia.

Ho: tidak terdapat pengaruh social media marketing terhadap brand image Tokopedia. 


\section{Hasil Temuan dan Diskusi}

Hasil akhir nilai rata-rata pada variabel X (social media marketing), dimensi komunikasi merupakan dimensi dengan nilai tertinggi, dan pada variabel Y (brand image) dimensi brand benefit and competence merupakan dimensi dengan nilai tertinggi.

Pada penelitian ini kuesioner telah terisi sebesar 218 responden. Pada 218 responden, responden yang mendominasi adalah berjenis kelamin perempuan. Pada segi umur, yang mendominasi adalah responden berumur 18-21 tahun dengan presentase sebesar 69,3\%. Dengan mayoritas responden yang mengetahui \#mulaiajadulu melalui media YouTube sebesar 33\%. Pada data 218 responden, peneliti telah dilakukan uji keabsahan data melalui uji validitas, dan uji reliabilitas untuk menguji 22 pernyataan yang ada pada kuesioner.

\begin{tabular}{ccccc}
\hline No. Soal & & R Hitung & R Tabel & Keterangan \\
\hline & P1 & 0,543 & 0,2 & Valid \\
& P2 & 0,474 & 0,2 & Valid \\
& P3 & 0,547 & 0,2 & Valid \\
& P4 & 0,423 & 0,2 & Valid \\
& P5 & 0,567 & 0,2 & Valid \\
X & P6 & 0,534 & 0,2 & Valid \\
& P7 & 0,474 & 0,2 & Valid \\
& P8 & 0,540 & 0,2 & Valid \\
& P9 & 0,260 & 0,2 & Valid \\
& P10 & 0,390 & 0,2 & Valid \\
& P11 & 0,352 & 0,2 & Valid \\
& P12 & 0,267 & 0,2 & Valid \\
& P13 & 0,399 & 0,2 & Valid \\
& P14 & 0,400 & 0,2 & Valid \\
& P15 & 0,423 & 0,2 & Valid \\
& P16 & 0,508 & 0,2 & Valid \\
& P17 & 0,531 & 0,2 & Valid \\
& P18 & 0,494 & 0,2 & Valid \\
Y19 & 0,542 & 0,2 & Valid \\
& P20 & 0,464 & 0,2 & Valid \\
& P21 & 0,474 & 0,2 & Valid \\
& P22 & 0,594 & 0,2 & Valid \\
\hline
\end{tabular}

\section{Uji Reliabilitas X}

Sesudah diuji dengan SPPS versi 22, hasil pada pernyataan variabel X (social media marketing) yakni senilai 0,794 . Pernyataan pada variabel $\mathrm{X}$ dapat termasuk pada hitungan reliabel, karena nilai Cronbach's Alpha > 0,6 yaitu 0,794 > 0,6.

Uji Reliabilitas Y

Sesudah diuji dengan SPPS versi 22, hasil pada pernyataan variabel Y (brand image) yakni senilai 0,805 . Pernyataan pada variabel $\mathrm{Y}$ dapat termasuk pada hitungan reliabel, karena nilai Cronbach's Alpha > 0,6 yaitu 0,805 > 0,6.

Hasil Analisis Data: 
Defrianto, Riris Loisa: Efektivitas Social Media Marketing E-Commerce Dalam Meningkatkan Brand Image Perusahaan (Survei Pada Pelanggan Tokopedia)

\section{Uji Koefisien Korelasi Sederhana}

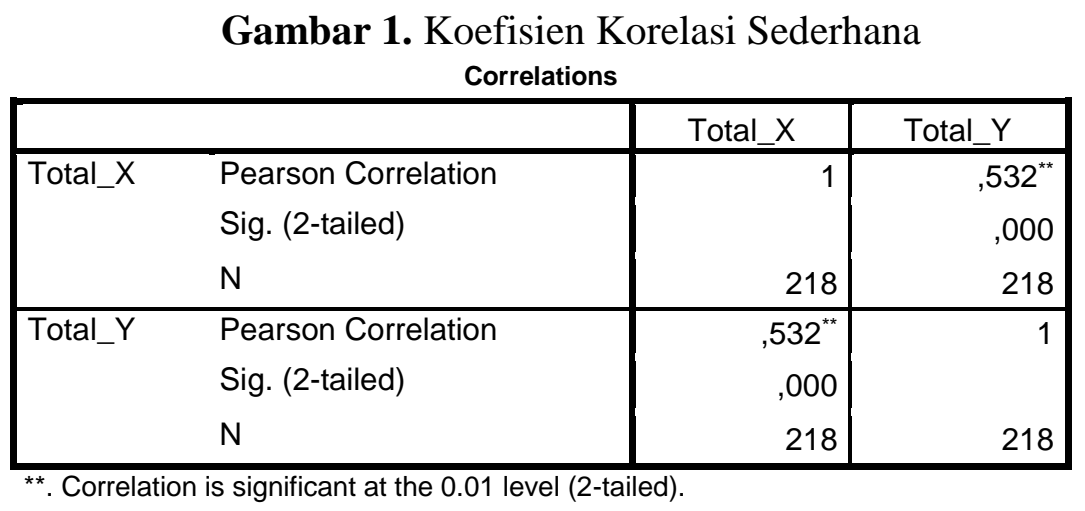

\section{Sumber: SPSS versi 22}

Sesudah diuji dengan SPPS versi 22, peneliti memperoleh hasil kalau koefisien korelasi sederhana pada variabel X (social media marketing) dan Y (brand image) sebesar 0,532. Menurut Sugiyono (2016), jika perolehan interval koefisien sebesar $0.40-0.599$ maka hubungan antara variabel $\mathrm{X}$ terhadap $\mathrm{Y}$ dalam penelitian ini adalah sedang.

\section{Uji Koefisien Determinasi}

Sesudah diuji menggunakan SPPS versi 22, peneliti mendapatkan hasil nilai koefisien determinasi dengan melihat angka yang pada R Square. Hasil dari R square adalah 0,283 sama dengan 28,3\% yang artinya kemampuan variabel-variabel independen (social media marketing) dalam mempengaruhi variabel dependen (brand image) tidak cukup kuat karena nilai koefisien determinasi tidak mendekati satu dan hasil koefisien determinasi di atas, dapat juga dikatakan bahwa citra merek Tokopedia dipengaruhi sebesar $28,3 \%$ oleh social media marketing, sementara sisanya $71,7 \%$ dipengaruhi oleh variabel-variabel lain.

Gambar 2. Koefisien Determinasi Model Summary

\begin{tabular}{|l|r|r|r|r|}
\hline Model & $\mathrm{R}$ & $\mathrm{R}$ Square & Adjusted R Square & $\begin{array}{c}\text { Std. Error of the } \\
\text { Estimate }\end{array}$ \\
\hline 1 &, $532^{\mathrm{a}}$ &, 283 &, 279 & 3,391 \\
\hline
\end{tabular}

\section{Sumber: SPSS versi 22}

\section{Uji Regresi Linear Sederhana}

Sesudah diuji dengan SPPS versi 22, peneliti mendapatkan hasil nilai sebesar 18,047 menyatakan konstanta dari fungsi regresi yang menampilkan jika tidak ada kenaikan pada variabel X (social media marketing), jadi variabel Y (brand image) akan mengalami peningkatan sebesar 0,408 dan setiap ada penambahan. Hal ini menunjukkan bahwa koefisien regresi bernilai (+), maka dengan demikian social media marketing (X) berpengaruh positif terhadap brand image. 
Coefficients $^{a}$

Gambar 3. Analisis Regresi Linear Sederhana dan Uji t

\begin{tabular}{|c|c|c|c|c|c|c|}
\hline \multirow{2}{*}{\multicolumn{2}{|c|}{ Model }} & \multicolumn{2}{|c|}{ Unstandardized Coefficients } & \multirow{2}{*}{$\begin{array}{c}\begin{array}{c}\text { Standardized } \\
\text { Coefficients }\end{array} \\
\text { Beta }\end{array}$} & \multirow[b]{2}{*}{$\mathrm{t}$} & \multirow[b]{2}{*}{ Sig. } \\
\hline & & $\mathrm{B}$ & Std. Error & & & \\
\hline \multirow[t]{2}{*}{1} & (Constant) & 18,047 & 1,662 & & 10,861 &, 000 \\
\hline & Total_X & ,408 & ,044 &, 532 & 9,225 &, 000 \\
\hline
\end{tabular}

a. Dependent Variable: Total_Y

Sumber: SPSS versi 22

$\mathbf{Y}=\mathbf{a}+\mathbf{b X}$

Sesudah diuji dengan SPSS versi 22, memperoleh nilai tabel yakni 1,988. Hasil

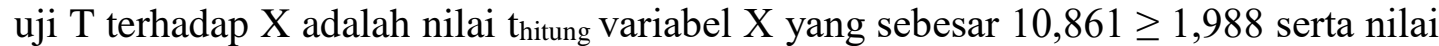
sig < $\alpha$ yaitu $0,000<0,05$, maka Ha diterima, artinya terdapat pengaruh social media marketing terhadap brand image Tokopedia.

\section{Simpulan}

Social media marketing adalah sebagai sebuah rencana dan metode dalam membentuk sebuah pengaruh dan reputasi perusahaan (Sinaga dalam Neti, 2017).

Dalam variabel social media marketing (X) terdapat empat dimensi yaitu, konteks, komunikasi, kolaborasi, dan koneksi lainnya (Rizal dan Lubis, dalam Heurer, 2014). Dimensi konteks dapat mempengaruhi brand image Tokopedia karena konten atau pesan yang disampaikan Tokopedia itu mempengaruhi citranya dan pesan yang disampaikan harus reliabel. Pada dimensi komunikasi, Tokopedia melakukan komunikasi yang baik melalui media sosialnya terhadap pengguna. Selain itu, pada dimensi kolaborasi Tokopedia telah melakukan kolaborasi baik dengan influencer yang sudah dikenal oleh masyarakat sehingga pesan maupun kampanyenya mudah diterima.

Dimensi komunikasi adalah dimensi yang tertinggi dalam mempengaruhi brand image, hal ini tentu karena komunikasi yang telah dilakukan Tokopedia melalui media sosial sudah baik bagi pengguna dan masyarakat.

Kesimpulan berdasarkan hasil penelitian dari penelitian ini adalah hasil uji koefisien korelasi terdapat hubungan antara brand image sebesar 0,532 yang artinya bahwa hubungan antara X dan Y dapat dikatakan sedang. Selain itu, berdasarkan hasil uji koefisien determinasi terdapat 0,283, yang berarti brand image Tokopedia dipengaruhi sebesar $28,3 \%$ oleh social media marketing sementara sisanya $71,7 \%$ dipengaruhi oleh variabel-variabel lain. Berdasarkan hasil uji regresi linear yaitu Y= $18,047+0,408 \mathrm{X}$, karena nilainya positif maka social media marketing $(\mathrm{X})$ memiliki pengaruh positif terhadap brand image (Y). Hasil signifikani yang didapat adalah $<0,005$, maka dapat dikatakan Ho ditolak dan Ha diterima, berarti bahwa "Ada pengaruh social media marketing $(\mathrm{X})$ terhadap brand image (Y)" 
Defrianto, Riris Loisa: Efektivitas Social Media Marketing E-Commerce Dalam Meningkatkan Brand Image Perusahaan (Survei Pada Pelanggan Tokopedia)

\section{Ucapan Terima Kasih}

Penulis mengucapkan terima kasih kepada Dekan Fakultas Ilmu Komunikasi Universitas Tarumanagara sekaligus merupakan Dosen Pembimbing peneliti yang telah meluangkan waktunya untuk membimbing peneliti serta kedua orang tua peneliti yang selalu menyemangati dan mendoakan peneliti, serta teman seperbimbingan peneliti Brigitta Novllia Jesslyn, Edwin Notowijoyo, Jessica Laurance, Lea Nia, Parousia, dan Reynaldi Rifaldo yang selalu mendukung dan memberikan semangat dalam proses penyusunan skripsi ini, serta responden yang telah mengisi kuesioner, dan sahabat penulis Devi Zalika, Heriyanti, Supriyadi, dan Vivi Anyati yang telah memberikan dukungan dan doa kepada peneliti.

\section{Daftar Pustaka}

Candraningrum, Diah Ayu., \& Sisca Aulia. (2019). Komunikasi Bisnis Argegator Media Di Era Digital. Laporan Penelitian.

https://aseanup.com/top-e-commerce-sites-indonesia/

https://www.jurnal.id/id/blog/mengenali-media-yang-digunakan-dalam-strategipemasaran-tradisional/

Kotler, P., \& Garry Armstrong. (2010). Prinsip-Prinsip Pemasaran, Jilid 1 dan 2 Edisi 12. Jakarta: Erlangga.

Kotler, P., \& Garry Armstrong. (2012). Prinsip-Prinsip Pemasaran, Jilid 1 dan 2 Edisi 13. Jakarta: Erlangga.

Kriyantono, R. (2016). Teknik Praktisi Riset Komunikasi: Disertai Contoh Praktis Riset Media, Public Relations, Komunikasi Organisasi, Komunikasi Pemasaran. Jakarta: Kencana Prenada Media Group.

Lucy Lee, J., James, J. D., \& Kyoum Kim, Y. (2014). A Reconceptualization of Brand Image. International Journal of Business Administration, 5(4). https://doi.org/10.5430/ijba.v5n4p1

Morissan. (2012). Periklanan Komunikasi Pemasaran Terpadu. Jakarta: Kencana Prenada Media Group.

Sinaga, D. (2017). Pengaruh Social Media Marketing Vlogger Instagram Terhadap Aktivitas Pengguna Instagram (Studi Korelasional Tentang Pengaruh Social Media Marketing Oleh Vlogger Instagram Terhadap Aktivitas Pengguna Instagram Mahasiswa Ilmu Komunikasi Universitas Sumatera.

Sugiyono. (2016). Metode Penelitian Kuantitatif, Kualitatif, dan R\&D. Bandung: CV Alfabeta.

Yulianti, T., Suryana, A., \& Zein, D. (2012). Hubungan Antara Brand Image dengan Keputusan Memilih Universitas Komputer Indonesia. Students E-Journal, $1(1), \quad 25 . \quad$ Retrieved from http://jurnal.unpad.ac.id/ejournal/article/view/1647/pdf_10 